\title{
Coumarins from the roots of Angelica dahurica cause anti-allergic inflammation
}

\author{
DONG $\mathrm{LI}^{1}$ and $\mathrm{LI} \mathrm{WU^{2 }}$ \\ ${ }^{1}$ Ear, Nose and Throat Department; ${ }^{2}$ Clinical Laboratory, \\ The First People's Hospital of Jingmen, Jingmen, Hubei 448000, P.R. China
}

Received April 12, 2016; Accepted March 17, 2017

DOI: $10.3892 /$ etm.2017.4569

\begin{abstract}
Allergic inflammation is induced by allergens and leads to various allergic diseases, including rhinitis, asthma and conjunctivitis. Histamine is important in the pathogenesis of an immunoglobulin E-dependent allergic reaction and results in the secretion of cytokines associated with inflammation. Angelica dahurica (A. dahurica) is a medicinal plant widely used in China for the treatment of symptoms related to allergic inflammation. The present study investigated the chemical constituents from A. dahurica and evaluated their reductive effect on allergic inflammation. As a result, 15 compounds including 13 coumarins have been identified as isoimperatorin (1), imperatorin (2), oxypeucedanin (3), oxypeucedanin hydrate (4), bergapten (5), byakangelicin (6), phellopterin (7), byakangelicol (8), isopimpinellin (9), xanthotoxol (10), xanthotoxin (11), pimpinellin (12), scopoletin (13), $\beta$-sitosterol (14) and daucosterol (15). Compounds 1-13 were able to reduce the release of histamine, with compounds 4-6 exhibiting the most potent activity. Furthermore, compounds 1-12 were able to inhibit the secretion of tumor necrosis factor- $\alpha$, interleukin (IL) $-1 \beta$ and IL-4, with compounds 5 and 7 exhibiting the strongest inhibitory effects. These compounds implemented the inhibitory effects on the expression of inflammatory cytokine genes through the inhibition of nuclear factor- $\kappa \mathrm{B}$ activation. Virtual screening by a docking program indicated that compound 3 is a potent histamine $\mathrm{H}_{1}$ receptor antagonist. Additionally, the calculated physicochemical properties of these compounds support most furanocoumarins to be delivered to binding sites and permeate the cell membrane. The present findings contribute to understanding how A. dahurica attenuates allergic inflammation.
\end{abstract}

Correspondence to: Professor Li Wu, Clinical Laboratory, The First People's Hospital of Jingmen, 67 Xiangshan Street, Jingmen, Hubei 448000, P.R. China

E-mail:wuli448000@126.com

Key words: Angelica dahurica, coumarins, allergic inflammation, histamine, inflammatory cytokines, physicochemical properties

\section{Introduction}

Allergic inflammation is caused by allergens and results in diseases, including rhinitis, asthma and conjunctivitis. It impacts the quality of life and costs large medical expenditures to attenuate the hypersensitive symptoms. In total, $10-20 \%$ of the population worldwide suffers from allergies, and this number annually increases (1). Similarly to effector cells, mast cells are important in allergic inflammation through the production and secretion of allergic mediators, including histamine, chemokines, cytokines and growth factors (2). When exposed to allergens the stimulation leads to the production of immunoglobulin $\mathrm{E}$ ( $\mathrm{IgE}$ ) within min, which binds to the IgE receptor on the surface of mast cells with high affinity (3) and induces IgE-dependent acute hypersensitivity reactions. Furthermore, crosslinking of antigen-IgE triggers the IgE receptor-mediated activation of mast cells and induces the degranulation of mast cells through granule membrane fusion (4). This is followed by the release of allergic inflammatory mediators, including histamine, chemokines, cytokines and eicosanoids for the change of membrane permeability (5). As a major allergic mediator, histamine is the most important molecule in acute allergy and acts by binding to the histamine $\mathrm{H}_{1}$ receptor, which manifests edema, warmth and erythema by causing vasodilation, increasing vascular permeability and leukocyte recruitment (6). Additionally, inflammatory cytokines such as tumor necrosis factor (TNF)- $\alpha$, interleukin (IL)- $1 \beta$ and IL- 4 , affect the chronic inflammatory phase by enhancing B cell survival or T cell activation (7). Furthermore, nuclear factor (NF)- $\kappa \mathrm{B}$ is an important transcriptional factor in inflammation and activated NF- $\mathrm{KB}$ is able to regulate gene expression of inflammatory cytokine genes, including TNF- $\alpha$, IL-1 $\beta$ and IL-4 (8). Finally, rat basophilic leukemia (RBL)-2H3 cells are suitable for in vitro studies of mast cell-mediated allergic inflammation, which involves the degranulation and expression of inflammatory cytokines $(9,10)$.

Angelica dahurica (A. dahurica; Fisch. ex Hoffm.) Benth. et Hook. f. ex Franch. et Sav (Umbelliferae) is a plant that belongs to the Angelica genus and is distributed in Northern and Northeastern China. In Traditional Chinese Medicine, the roots of A. dahurica have been used to treat headache, rhinitis, cold and toothache amongst others. Furthermore, pharmacological studies have shown that it has antimicrobial (11), hepatoprotective (12), antioxidative (13) and cholinesterase 
inhibitory activities (14), and activates dendritic cells (15) and the actions of lipolytic hormones (16). Furthermore, it inhibits the production of prostaglandin $\mathrm{E}_{2}(17)$ and nitric oxide (NO) $(18,19)$, and reduces the release of histamine (20). In addition, the ethanolic extract of $A$. dahurica displayed anti-inflammatory effects by the upregulation of heme oxygenase-1, particularly in mice with asthma $(21,22)$. Phytochemical investigations have revealed that there were coumarins $(23,24)$ in $A$. dahurica as well as lignans $(25)$, polyacetylene (26) and polysaccharides (15). The aim of the present study was to search bioactive phytochemicals for the treatment of allergic inflammatory diseases. Various chemical constituents in A. dahurica were isolated and relevant effects on allergic inflammation were evaluated.

\section{Materials and methods}

Plant materials. The roots of A. dahurica were purchased from Bozhou Materia Medica Market (Bozhou, China) in 2012 and identified at that institution. The voucher specimen (M20120907) was deposited in The Firs People's Hospital of Jingmen City (Jingmen, China).

Chemicals and reagents. Water was prepared from distilled water by a Milli-Q system (EMD Millipore, Billerica, MA, USA). Anti-dinitrophenyl (DNP)-IgE (D8406) and DNP-human serum albumin (D-5059-10) were purchased from Sigma-Aldrich (Merck KGaA, Darmstadt, Germany). The media and reagents for the cell culture were supplied by Gibco (Thermo Fisher Scientific, Inc., Waltham, MA, USA). ELISA kits for TNF- $\alpha$ (H052), IL-1 $\beta$ (H002) and IL-4 (H005) were purchased from the Nanjing Jiancheng Bioengineering Institute (Nanjing, China). The luciferase assay system including $\mathrm{NF}-\kappa \mathrm{B}$ luciferase reporter plasmid pGL4.32 and the Renilla luciferase reporter vector plasmid pRL-TK was supplied by Promega Corporation (Madison, WI, USA). The Lipofectamine ${ }^{\circledR} 2000$ transfection reagent was purchased from Invitrogen (Thermo Fisher Scientific, Inc.). The other solvents employed in the present study were of analytical purity grade. Sephadex LH-20 was purchased from GE Healthcare Life Sciences (Chalfont, UK), Toyopearl HW-40C from Tosoh Corp. (Tokyo, Japan), silica gel from Qingdao Ocean Chemical Co., Ltd. (Qingdao, China) and octadecylsilane (ODS) was supplied by Daiso Chemical Co., Ltd. (Osaka, Japan). Porous resin $\mathrm{D}_{101}$ was obtained from Tianjin Blosorb Biotechnology Co., Ltd. (Tianjin, China).

Extraction and isolation. The dried roots of $A$. dahurica $(10.0 \mathrm{~kg})$ were ground and extracted with 95\% ethanol (20 1 each time) under reflux for $5 \mathrm{~h}$ three times. Following evaporation of the solvent under reduced pressure, the residue was obtained and suspended in water $(5.0$ 1) followed by successive partition with petroleum ether (PE; 5.01 each time), ethyl acetate (EA; 5.01 each time) and $n$-butanol $(n-\mathrm{BuOH} ; 5.01$ each time) for three times. Subsequently, the solvents were removed and three parts were obtained.

The PE part (110.0 g) was subjected to column chromatography $(\mathrm{CC})$ on a silica gel eluted with gradient $\mathrm{PE} / \mathrm{EA}$ (from 100:0 to 20:80, v/v) and 6 fractions were obtained according to the thin-layer chromatography (TLC) assay results. Briefly, the samples in EA were loaded on the TLC plates (Qingdao Jiyida Silica Reagent Co., Ltd., Qingdao, China) and eluted with PE/EA (70:30, v/v). The spots were visualized under ultraviolet light. Fraction 3 was further separated by silica gel $\mathrm{CC}$ to produce compound $14(25.0 \mathrm{mg})$ as colorless needle-like crystals. Fraction 5 was also isolated on a silica gel CC to obtain compound $13(10.5 \mathrm{mg})$, and fraction 6 was subjected to $\mathrm{HW}-40 \mathrm{C}$ and eluted with isocratic dichloromethane methanol (DCM/MeOH; 3:1, v/v) to produce compound 1 (33.0 mg).

The EA extract $(260.0 \mathrm{~g})$ was subjected to silica gel CC and eluted by gradient DCM/MeOH (from 100:0 to 0:100, v/v). Furthermore, the eluate was combined into 12 fractions based on the TLC assay. Fraction 2 was subjected to the HW-40C CC eluted with isocratic DCM/MeOH $(2: 1, \mathrm{v} / \mathrm{v})$ and then recrystallized to produce compounds $4(33.7 \mathrm{mg})$ and $6(15.5 \mathrm{mg})$. Fractions 3 and 4 were combined and separated on the silica gel CC with gradient DCM/MeOH (from 90:0 to 50:50, v/v) to produce four subfractions. Subfractions 2 and 4 were further purified with Sephadex LH-20 eluted with DCM/MeOH $(50: 50, \mathrm{v} / \mathrm{v})$ and compounds $1(81.0 \mathrm{mg})$ and $2(63.0 \mathrm{mg})$ were obtained. Fraction 6 was repeatedly subjected to silica gel $\mathrm{CC}$ with $\mathrm{DCM} / \mathrm{MeOH}$ as the eluent, and the eluates were subsequently crystalized to produce compounds 7 (21.0 $\mathrm{mg})$, $5(18.0 \mathrm{mg})$ and $11(11.0 \mathrm{mg})$. Fraction 8 was disposed by the silica gel $\mathrm{CC}$ with gradient $\mathrm{DCM} / \mathrm{MeOH}$ and subsequently Sephadex LH-20 CC eluted with isocratic DCM/MeOH (1:1, $\mathrm{v} / \mathrm{v})$ to produce compounds $9(9.5 \mathrm{mg})$ and $10(13.0 \mathrm{mg})$. Fraction 9 was purified by the Sephadex LH-20 CC directly and then preparative TLC to obtain compound $12(8.5 \mathrm{mg})$. Finally, fraction 11 was separated on an ODS CC eluted with $\mathrm{MeOH} / \mathrm{H}_{2} \mathrm{O}$ (50:50 to 95:5, v/v) and purified by Sephadex $\mathrm{LH}-20 \mathrm{CC}$ eluted with $\mathrm{MeOH}$ to gain compounds 3 (12.5 mg) and $8(13.0 \mathrm{mg})$.

The $n$-BuOH extract (130.0 g) was subjected to porous resin $\mathrm{D}_{101} \mathrm{CC}$ with gradient ethanol/ $\mathrm{H}_{2} \mathrm{O}(10: 90,30: 60,90: 10$ and $100: 0, \mathrm{v} / \mathrm{v})$ to produce 4 fractions. Fraction 1 was separated on ODS CC eluted with $\mathrm{MeOH} / \mathrm{H}_{2} \mathrm{O}$ (from 30:70 to 95:5, $\mathrm{v} / \mathrm{v})$ to produce compounds 1 (16.5 mg), $3(10.5 \mathrm{mg})$ and 4 (13.0 mg). Furthermore, fraction 2 was also subjected to ODS CC to produce compound 15 (26.0 mg).

The compounds isolated were dissolved in DMSO and the nuclear magnetic resonance (NMR) spectra were recorded on a Bruker DRX400 NMR spectrometer (Bruker, Billerica, MA, USA) to elucidate their chemical structures. Mass spectrometry was performed on Agilent LC-MS with 1260 LC system and 6400 Series Triple Quadrupole mass spectrometer equipped with electrospray ionization (Agilent Technologies, Santa Clara, CA, USA). The structures were determined through comparing the data obtained from NMR and MS with those in previously published literature (see Results).

Cell culture. RBL-2H3 cells were purchased from the Type Culture Collection of the Chinese Academy of Sciences (Shanghai, China). Cells were cultured in Dulbecco's modified Eagle's medium supplemented with $10 \%$ fetal bovine serum, $100 \mathrm{U} / \mathrm{ml}$ penicillin and $100 \mu \mathrm{g} / \mathrm{ml}$ streptomycin at $37^{\circ} \mathrm{C}$ in a humidified $5 \% \mathrm{CO}_{2}$ atmosphere.

Determination of released histamine. As the levels of histamine represented the degree of mast cell degranulation, the 
histamine contents in culture media were measured. The $o$-phthaldialdehyde spectrofluorometric procedure was employed as previously described (26). For the IgE-mediated histamine release, RBL-2H3 cells $\left(1 \times 10^{5}\right.$ cells/well in a $96-w e l l$ plate) were sensitized with anti-DNP IgE in PBS $(10 \mu \mathrm{g} / \mathrm{ml})$ and incubated at $37^{\circ} \mathrm{C}$ overnight. Next, the cells were pretreated with compounds obtained from the plant $(20 \mu \mathrm{M}$ in PBS containing $0.1 \%$ DMSO) or PBS containing $0.1 \%$ DMSO at $37^{\circ} \mathrm{C}$ for $1 \mathrm{~h}$ prior to the challenge with DNP-human serum albumin (HSA; $500 \mathrm{ng} / \mathrm{ml}$ ). The cells were then separated from the media by centrifugation at $10,000 \times \mathrm{g}$ for $5 \mathrm{~min}$ at $4^{\circ} \mathrm{C}$. Furthermore, the fluorescent intensity was recorded by a fluorescent plate reader (Molecular Devices, LLC, Sunnyvale, CA, USA) at an excitation wavelength of $360 \mathrm{~nm}$ and an emission wavelength of $440 \mathrm{~nm}$.

Molecular modeling for screening the histamine $H_{1}$ receptor antagonists. Molecular docking is able to provide the visual detail of the interaction between a ligand and a biomacromolecule. In the present study the Surflex-Dock Sybyl v2.0 program (Tripos Inc., St. Louis, MO, USA) was used. 3D structures of the compounds obtained were prepared by Sybyl sketch and optimized by Tripos force field. The crystal structure of the histamine $\mathrm{H}_{1}$ receptor was retrieved from the RSCB Protein Data Bank (www.rcsb.org/pdb/home/home.do) (PDB code: 3RZE), and hydrogen atoms and charges were added. After removing the water, the docking process was performed (27).

Measurements for levels of TNF- $\alpha, I L-1 \beta$ and IL-4. The levels of inflammatory cytokines in the media from RBL-2H3 cells challenged with DNP-HSA were determined by ELISA. ELISA was performed on a 96-well plate using ELISA kits according to the manufacturer's instructions. After terminating the reaction of the substrate through the addition of stop buffer $\left(2 \mathrm{~N} \mathrm{H}_{2} \mathrm{SO}_{4}\right)$, the absorbance was recorded on a spectrophotometer at a wavelength of $450 \mathrm{~nm}$.

Dual luciferase reporter assay for $N F-\kappa B$ activity. RBL-2H3 cells $\left(1 \times 10^{6}\right.$ cells/well in a 24 -well plate) were transfected with both the NF- $\mathrm{B}$ luciferase reporter plasmid pGL4.32 and the Renilla luciferase reporter vector plasmid pRL-TK at 100 and 9.6 ng per well, respectively. Following transfection using lipofectamine ${ }^{\circledR} 2000$ at $37^{\circ} \mathrm{C}$ for $24 \mathrm{~h}$, the medium was replaced with fresh serum-free medium. Cells were treated with compounds obtained from the plant $(20 \mu \mathrm{M}$ in PBS containing $0.1 \%$ DMSO) or PBS containing $0.1 \%$ DMSO before stimulation. Cells were subsequently washed with PBS twice and lysed with PLB for 20 min according to the manufacturer's instructions for the luciferase reporter assay system. The Promega protocol was run on the GloMax-Multi JR detection system (Promega Corporation). Briefly, $50 \mu$ l luciferase assay reagent was mixed with $10 \mu \mathrm{l}$ lysate. The fluorescence intensity of firefly luciferase was determined. Then $50 \mu \mathrm{l}$ Stop \& Glo ${ }^{\circledR}$ reagent was added into the mixture and the fluorescence intensity of Renilla luciferase was measured. Furthermore, the relative luciferase activity was measured by normalizing the firefly luciferase activity against the internal control (Renilla luciferase).

Physicochemical properties of the compounds. Lipophilicity/hydrophilicity has a strong influence on the absorption, distribution, metabolism and excretion properties of pharmacological agents in vivo. Hydrophobic agents tend to bind to hydrophobic sites whereas hydrophilic ones favor hydrophilic positions (28). Therefore, the lipophilicity/hydrophilicity expressed as $\log p$ was theoretically calculated through the physicochemical module of the Sybyl program while inputting the chemical structures to elucidate the physicochemical properties of these compounds. Generally, the values of $\log p$ for the drugs are between 2 and 5, which suggests that the drugs may be easily delivered to binding sites.

The polar surface area (PSA) derived from the Sybyl program as above is defined as the surface sum over all polar atoms, primarily oxygen and nitrogen atoms, also including their attached hydrogen atoms. It is typically used to optimize a drug's ability to permeate cells. Furthermore, molecules with PSA values of $<140 \AA^{2}$ tend to be poor at permeating cell membranes.

Statistical analysis. All values are expressed as the mean \pm standard deviation, and GraphPad Prism 5.0 (GraphPad Software, Inc., La Jolla, CA, USA) was used for statistical analysis. Significant differences of experimental data from different groups were compared by one way analysis of variance followed by Dunnet's test for multiple comparisons and Student's t-test for single comparisons. $\mathrm{P}<0.05$ was considered to indicate a statistically significant difference.

\section{Results}

Phytochemical investigation. Phytochemical investigation on the roots of $A$.dahurica has led to the isolation of 15 compounds. As shown in Fig. 1, their structures were identified as isoimperatorin (1) (29), imperatorin (2) (29), oxypeucedanin (3) (30), oxypeucedanin hydrate (4) (29), bergapten (5) (29), byakangelicin (6) (29), phellopterin (7) (29), byakangelicol (8) (31), isopimpinellin (9) (32), xanthotoxol (10) (29), xanthotoxin (11) (29), pimpinellin (12) (31), scopoletin (13) (31), $\beta$-sitosterol (14) (29) and daucosterol (15) (29) on the basis of spectra analysis including ${ }^{1} \mathrm{H}$-nuclear magnetic resonance (NMR), ${ }^{13} \mathrm{C}$-NMR and mass spectrometry in combination with the data comparison from previously published studies (29-32).

Contents of released histamine. The contents of released histamine in the media for RBL-2H3 cells indicated mast cell degranulation. As shown in Fig. 2, anti-DNP IgE-sensitized RBL-2H3 cells released a significantly increased level of histamine when DNP-HSA was added, compared with control cells. Compounds 1-13 significantly reduced the content of histamine in the media, compared with DNP-HSA cells, compound 5 induced the greatest decrease of the three.

Docking studies for the coumarins with histamine $H_{1}$ receptor. Molecular docking revealed the interaction between the histamine $\mathrm{H}_{1}$ receptor and isolated coumarins. Out of all the coumarins, compound 3 exhibited a more potent affinity to the histamine $\mathrm{H}_{1}$ receptor than the others. Its total score (a measure of its affinity recorded by the Sybyl program) was 8.46, which was higher than for doxepin (a ligand in the crystal structure of the histamine $\mathrm{H}_{1}$ receptor) which had a total score of 7.57. In addition, compounds 1, 2, 4 and 6 
A

$\begin{array}{lll} & \mathrm{R}_{1} & \mathrm{R}_{2} \\ \mathbf{1} & \mathrm{G}_{1} & \mathrm{H} \\ \mathbf{2} & \mathrm{H} & \mathrm{G}_{1} \\ \mathbf{3} & \mathrm{G}_{3} & \mathrm{H} \\ \mathbf{4} & \mathrm{G}_{2} & \mathrm{H} \\ \mathbf{5} & \mathrm{OCH}_{3} & \mathrm{H} \\ \mathbf{6} & \mathrm{OCH}_{3} & \mathrm{G}_{2} \\ \mathbf{7} & \mathrm{OCH}_{3} & \mathrm{G}_{1} \\ \mathbf{8} & \mathrm{OCH}_{3} & \mathrm{G}_{3} \\ \mathbf{9} & \mathrm{OCH}_{3} & \mathrm{OCH}_{3} \\ 10 & \mathrm{H} & \mathrm{OH} \\ \mathbf{1 1} & \mathrm{H} & \mathrm{OCH}_{3}\end{array}$

B<smiles></smiles><smiles>[R1]c1c2ccc(=O)oc2c([R])c2ccoc12</smiles><smiles>C1=CCOC2C=C2CC1</smiles>

$\mathrm{G}_{2}=$<smiles>CC(C)(O)C(O)CO</smiles>

$\mathrm{G}_{3}=$<smiles>CC1(C)OC1CO</smiles>

C<smiles>COc1cc2ccc(=O)oc2cc1O</smiles>

13

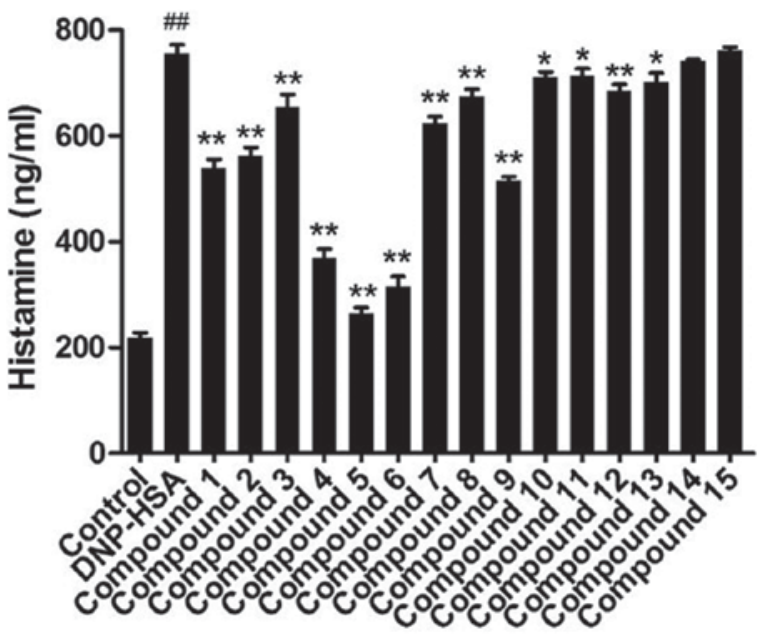

Figure 2. Effects of compounds isolated from Angelica dahurica on the histamine release in the media of mast cells. ${ }^{\# \#} \mathrm{P}<0.01$ vs. control group; ${ }^{*} \mathrm{P}<0.05,{ }^{* *} \mathrm{P}<0.01$ vs. DNP-HSA group. DNP-HSA, dinitrophenyl-human serum albumin.

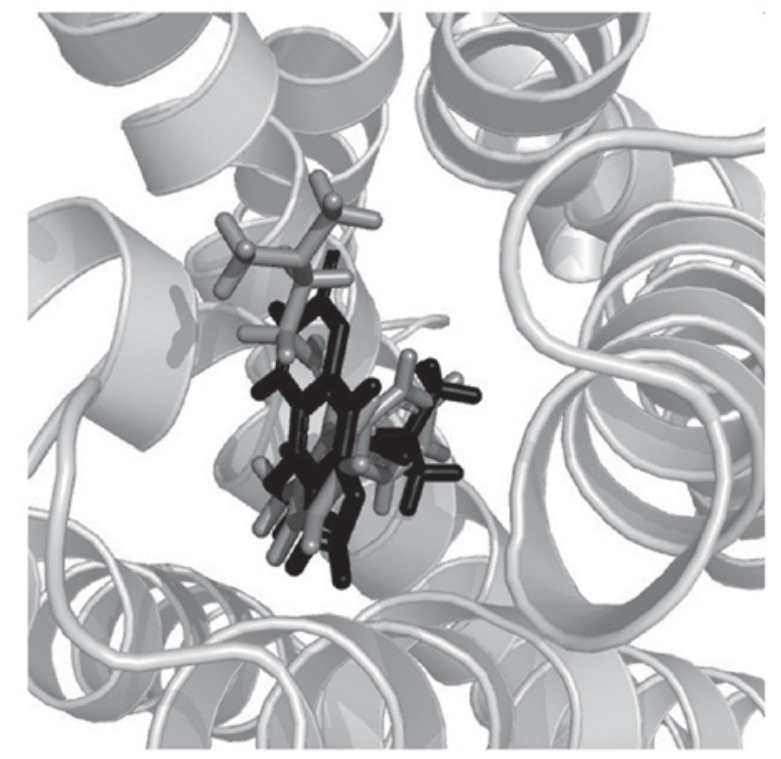

Figure 3. Stereoview of compound 3 (black) and doxepin (gray) in the binding pocket.

whereas the scores for compounds 7 and 8 were 5.81 and 5.77, respectively. As shown in Fig. 3, compound 3 is able to fully enter the binding pocket of histamine $\mathrm{H}_{1}$ receptor and present a similar pose with doxepin. Hydrophobic and electrostatic interactions are important for the formation of the ligand-receptor complex (Fig. 4), although there are no evident hydrogen bonds between small molecules and biomacromolecules.

Levels of inflammatory cytokines. To further evaluate the compounds from A. dahurica on chronic allergic inflammation, the levels of TNF- $\alpha$, IL- $1 \beta$ and IL- 4 in the media for RBL-2H3 cells were determined (Fig. 5). Following challenge with DNP-HSA, the levels of TNF- $\alpha$, IL-1 $\beta$ and IL-4 in the media significantly increased compared with control cells. When pretreated with the obtained compounds, the levels of TNF- $\alpha$, IL- $1 \beta$ and IL-4 for compounds 1-12 were significantly decreased compared with DNP-HSA cells, to different extents. Compounds 1,2,5 and 7 induced the greatest decrease in levels of these inflammatory cytokines. However, compounds 13-15 exhibited no significant difference on TNF- $\alpha$, IL-1 $\beta$ and IL-4.

Activation of $N F-\kappa B$. In order to further confirm the effects of these compounds on the expression of inflammatory cytokine genes, the activation of $\mathrm{NF}-\kappa \mathrm{B}$ was investigated following treatment with these compounds. As a result, the activation of NF- $\kappa \mathrm{B}$ was significantly increased in RBL-2H3 cells stimulated by DNP-HSA and significantly ameliorated when compounds 1-12 were administered (Fig. 6). Of all the compounds, compounds 5 and 7 exhibited the greatest potency, followed by compounds 1 and 2 .

Physicochemical properties of the compounds. As shown in Table I, the values of $\log p$ for the identified compounds 1-3, 5 and 7-11 were between 2 and 5. Conversely, the values of 

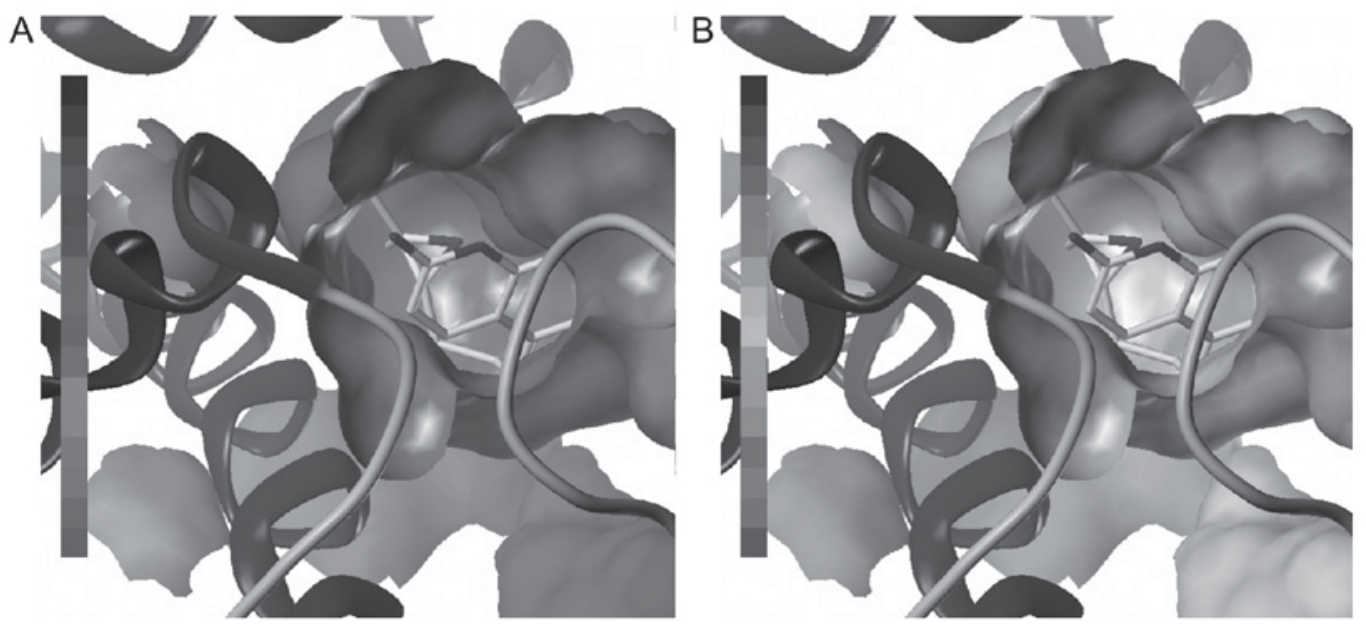

Figure 4. (A) Hydrophobic and (B) electrostatic interactions between compound 3 and the histamine $\mathrm{H}_{1}$ receptor. The scale bars in the figures represent (A) hydrophobicity/hydrophilicity (from top to bottom) or (B) positive charge/neutral/negative charge (from top to bottom).
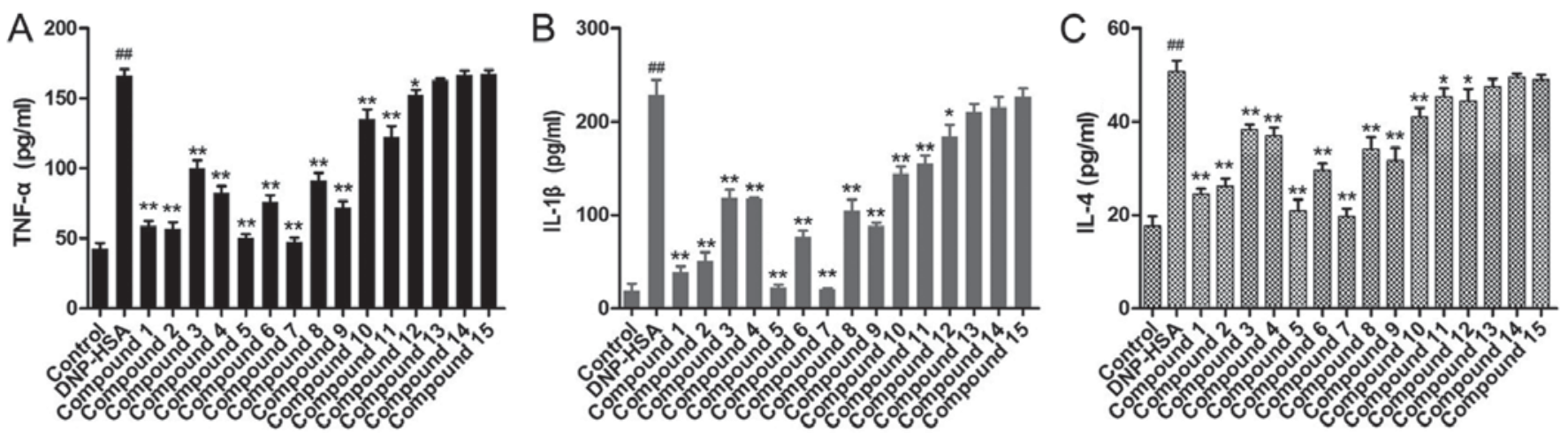

Figure 5. Effects of compounds obtained on the secretion of (A) TNF- $\alpha$, (B) IL-1 $\beta$ and (C) IL-4. ${ }^{\# \#} \mathrm{P}<0.01$ vs. control group; ${ }^{*} \mathrm{P}<0.05,{ }^{* *} \mathrm{P}<0.01$ vs. DNP-HSA group. TNF, tumor necrosis factor; IL, interleukin; DNP-HSA, dinitrophenyl-human serum albumin.

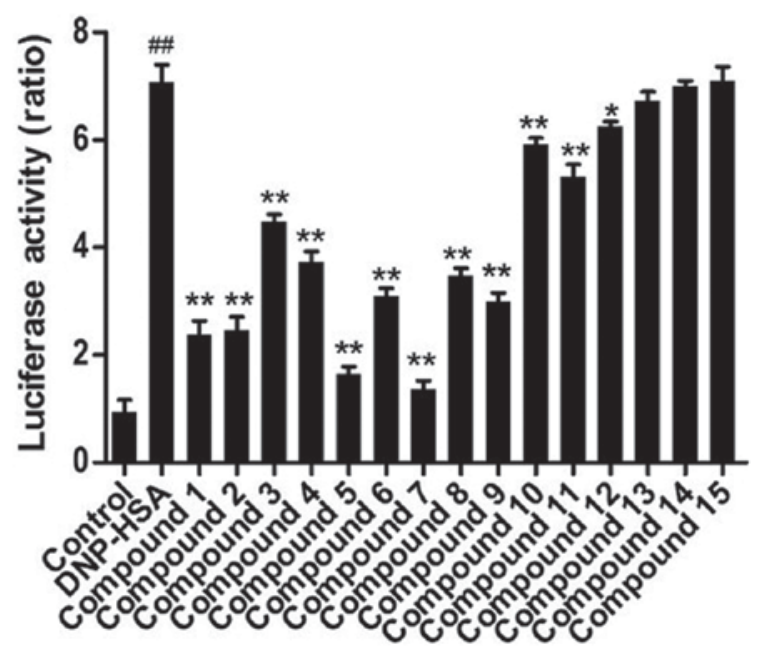

Figure 6. Effects of compounds obtained on the activation of nuclear factor- $\kappa \mathrm{B} .{ }^{\# \#} \mathrm{P}<0.01$ vs. control group, ${ }^{*} \mathrm{P}<0.05,{ }^{* *} \mathrm{P}<0.01$ vs. DNP-HSA group.

compounds 4, 6 and 12-15 were not within that range. In addition, the PSA values of these compounds were $<140$ besides compounds 6 and 15 . However, the PSA of compound 15 was markedly higher than that of compound 6 .

\section{Discussion}

A phytochemical investigation on the roots of A. dahurica resulted in the identification of 15 compounds. Of all the compounds, there were 13 coumarins identified. In the structures of compounds 1-11 the furan ring was fused at the C-6 and C-7 positions of the coumarin scaffold, and at the C-7 and C-8 positions in compound 12 to form furanocoumarins.

Pharmacological evaluation of these compounds has shown that compounds 1-13 are able to affect the release of histamine and these results indicate that the constituents in $A$. dahurica are able to inhibit the degranulation of mast cells. Furthermore, compounds 1-12 are able to reduce the secretion of TNF- $\alpha$, IL-1 $\beta$ and IL- 4 . It may be demonstrated that the 6,7-furanocoumarin scaffold is necessary and the methoxyl group at the C-5 position contributes largely to the decrease of histamine release, which is in accordance with the in vivo results for several coumarins of A. dahurica (20). Although isopentane-derived groups are likely to reduce the inhibition of histamine release, the 2,3-dihydroxyisopentane group has little effects on this. Similarly, the 6,7-furanocoumarin scaffold is necessary and the methoxyl group at the $\mathrm{C}-5$ position largely contributes to reduce the secretion of TNF- $\alpha$, IL- $1 \beta$ 
Table I. Physicochemical properties of compounds isolated from Angelica dahurica.

\begin{tabular}{lccr}
\hline Compound & MW $(\mathrm{Da})$ & $\log p$ & PSA $\left(\AA^{2}\right)$ \\
\hline 1 & 270.28 & 4.01 & 94.86 \\
2 & 270.28 & 4.01 & 75.46 \\
3 & 300.31 & 3.25 & 121.64 \\
4 & 318.32 & 1.71 & 139.58 \\
5 & 216.19 & 2.31 & 96.88 \\
6 & 348.35 & 1.74 & 142.93 \\
7 & 300.31 & 4.04 & 78.03 \\
8 & 330.33 & 3.28 & 97.99 \\
9 & 246.22 & 2.33 & 86.29 \\
10 & 202.16 & 2.18 & 139.43 \\
11 & 216.19 & 2.31 & 81.86 \\
12 & 246.22 & 1.98 & 85.57 \\
13 & 192.19 & 1.31 & 115.89 \\
14 & 365.32 & -6.08 & 65.77 \\
15 & 520.40 & -3.23 & 227.64 \\
\hline
\end{tabular}

MW, molecular weight; PSA, polar surface area.

and IL-4, which is in accordance with the previous results on anti-inflammatory coumarins in A. dahurica $(18,33,34)$. The isopentenyl group also shows a positive effect on the secretion of cytokines, which makes compounds 1 and 2 display potent activity. In addition, the present study has assessed the inhibitory effects of these compounds on NF- $\mathrm{B}$ activation. The results are also consistent with the inhibitory effects on the secretion of TNF- $\alpha$, IL-1 $\beta$ and IL-4. Finally, the results imply that these compounds inhibit expression of inflammatory cytokine genes by decreasing the activation of $\mathrm{NF}-\kappa \mathrm{B}$.

Virtual screening by docking indicates that compound 3 is a potent histamine $\mathrm{H}_{1}$ receptor antagonist together with some weak ligands to that protein compared with the intrinsic ligand. This may contribute to the molecular shape of compound 3 and its polarization. In addition, calculated $\log p$ and PSA support the majority of furanocoumarins in A. dahurica that are able to permeate the cell membrane and be delivered to the binding sites. Substituted groups also contribute to the $\log p$ values according to their polarities, and groups affecting the $\log p$ values are epoxy isopentenyl, 3,4-dihydroxy isopentenyl, methoxyl and isopentenyl. Similarly, the substituted groups affect the PSA value of the whole molecule. Of all these groups, 3,4-dihydroxy isopentanyl contributes mostly to PSA due to its abundance of oxygen atoms, resulting in compound 4 having a PSA $\sim 140$ and that of compound $6>140$. Furthermore, The PSA of compound 10 is close to 140 , which may be attributed to the intramolecular hydrogen bond between the hydroxyl and neighbor oxygen.

In conclusion, the present study suggests that coumarins in A. dahurica are able to alleviate acute allergy following chronic inflammatory reaction and indicates that anti-allergic inflammation of this medicinal plant results from the multiple effects of these compounds.

\section{Acknowledgements}

The authors would like to thank Dr Y Wang at Xiamen University (Xiamen, China) for his assistance in molecular modeling and calculation.

\section{References}

1. Erb KJ: Can helminths or helminth-derived products be used in humans to prevent or treat allergic diseases? Trends Immunol 30: 75-82, 2009.

2. Kraft S and Kinet JP: New developments in FcepsilonRI regulation, function and inhibition. Nat Rev Immunol 7: 365-378, 2007.

3. Galli SJ and Tsai M: IgE and mast cells in allergic disease. Nat Med 18: 693-704, 2012.

4. Castle JD, Guo Z and Liu L: Function of the t-SNARE SNAP-23 and secretory carrier membrane proteins (SCAMPs) in exocytosis in mast cells. Mol Immunol 38: 1337-1340, 2002.

5. Galli SJ, Kalesnikoff J, Grimbaldeston MA, Piliponsky AM, Williams CM and Tsai M: Mast cells as 'tunable' effector and immunoregulatory cells: Recent advances. Annu Rev Immunol 23: 749-786, 2005.

6. Galli SJ, Tsai M and Piliponsky AM: The development of allergic inflammation. Nature 454: 445-454, 2008.

7. Kay AB: Allergy and allergic diseases. First of two parts. New Eng J Med 344: 30-37, 2001.

8. Hayden MS and Ghosh S: NF-кB in immunobiology. Cell Res 21: 223-244, 2011

9. Bae Y, Lee S and Kim SH: Chrysin suppresses mast cell-mediated allergic inflammation: Involvement of calcium, caspase-1 and nuclear factor- $\kappa$ B. Toxicol Appl Pharm 254: 56-64, 2011.

10. Je IG, Kim DS, Kim SW, Lee S, Lee HS, Park EK, Khang D and Kim SH: Tyrosol suppresses allergic inflammation by inhibiting the activation of phosphoinositide 3-kinase in mast cells. PLoS One 10: e0129829, 2015.

11. Kwon YS, Kobayashi A, Kajiyama SI, Kawazu K, Kanzaki H and Kim CM: Antimicrobial constituents of Angelica dahurica roots. Phytochemistry 44: 887-889, 1997.

12. Oh H, Lee HS, Kim T, Chai KY, Chung HT, Kwon TO, Jun JY, Jeong OS, Kim YC and Yun YG: Furocoumarins from Angelica dahurica with heptaprotective activity on tacrine-induced cytotoxicity in Hep G2 cells. Planta Med 68: 463-464, 2002.

13. Cao Y, Zhang Y, Wang N and He L: Antioxidant effect of imperatorin from Angelica dahurica in hypertension via inhibiting NADPH oxidase activation and MAPK pathway. J Am Soc Hypertens 8: 527-536, 2014.

14. Seo WD, Kim JY, Ryu HW, Kim JH, Han SI, Ra JE, Seo KH, Jang $\mathrm{KC}$ and Lee JH: Identification and characterisation of coumarins from the roots of Angelica dahurica and their inhibitory effects against cholinesterase. J Funct Foods 5: 1421-1431, 2013.

15. Kim HS, Shin BR, Lee HK, Park YS, Liu Q, Kim SY, Lee MK, Hong JT, Kim Y and Han SB: Dendritic cell activation by polysaccharide isolated from Angelica dahurica. Food Chem Toxicol 55: 241-247, 2013.

16. Kimura Y, Ohminami H, Arichi H, Okuda H, Baba K, Kozawa M and Arichi S: Effects of various coumarins from roots of Angelica dahurica on actions of adrenaline, ACTH and insulin in fat cells. Planta Med 45: 183-187, 1982.

17. Ban HS, Lim SS, Suzuki K, Jung SH, Lee S, Lee YS, Shin KH and Ohuchi K: Inhibitory effects of furanocoumarins isolated from the roots of Angelica dahurica on prostaglandin $\mathrm{E}_{2}$ production. Planta Med 69: 408-412, 2003.

18. Deng GG, Wei W, Yang XW, Zhang YB, Xu W, Gong NB, Lü Y and Wang FF: New coumarins from the roots of Angelica dahurica var. formosana cv. Chuanbaizhi and their inhibition on NO production in LPS-activated RAW264.7 cells. Fitoterapia 101: 194-200, 2015.

19. Yang WQ, Song YL, Zhu ZX, Su C, Zhang X, Wang J, Shi SP and Tu PF: Anti-inflammatory dimeric furanocoumarins from the roots of Angelica dahurica. Fitoterapia 105: 187-193, 2015.

20. Kimura Y and Okuda H: Histamine-release effectors from Angelica dahurica var. Dahurica root. J Nat Prod 60: 249-251, 1997.

21. Lee MY, Lee JA, Seo CS, Ha H, Lee H, Son JK and Shin HK: Anti-inflammatory activity of Angelica dahurica ethanolic extract on RAW264.7 cells via upregulation of heme oxygenase-1. Food Chem Toxicol 49: 1047-1055, 2011. 
22. Lee MY, Seo CS, Lee JA, Lee NH, Kim JH, Ha H, Zheng MS, Son JK and Shin HK: Anti-asthmatic effects of Angelica dahurica against ovalbumin-induced airway inflammation via upregulation of heme oxygenase-1. Food Chem Toxicol 49: 829-837, 2011

23. Qiao SY, Yao XS and Wang ZY: Coumarins of the roots of Angelica dahurica. Planta Med 62: 584, 1996.

24. Kang J, Zhou L, Sun J, Han J and Guo DA: Chromatographic fingerprint analysis and characterization of furocoumarins in the roots of Angelica dahurica by HPLC/DAD/ESI-MSn technique. J Pharm Biomed Anal 47: 778-785, 2008.

25. Zhao XZ, Feng X, Jia XD, Dong YF and Wang M: Neolignan glycoside from Angelica dahurica. Chin Chem Lett 18: 168-170, 2007.

26. Lechner D, Stavri M, Oluwatuyi M, Pereda-Miranda R and Gibbons S: The anti-staphylococcal activity of Angelica dahurica (Bai Zhi). Phytochemistry 65: 331-335, 2004.

27. Zhao XR, Huo XK, Dong PP, Wang C, Huang SS, Zhang BJ, Zhang HL, Deng S, Liu KX and Ma XC: Inhibitory effects of highly oxygenated lanostane derivatives from the fungus Ganoderma lucidum on P-glycoprotein and $\alpha$-glucosidase. J Nat Prod 78: 1868-1876, 2015.

28. Damu GL, Cui SF, Peng XM, Wen QM, Cai GX and Zhou CH: Synthesis and bioactive evaluation of a novel series of coumarinazoles. Bioorg Med Chem Lett 24: 3605-3608, 2014.
29. Liang B, Xu L, Zou Z and Yang S: Chemical constituents isolated from Angelica dahurica var. formosana. Chin Trad Herb Drugs 36: 1132-1137, 2005

30. Hata K, Kozawa M, Yen K and Kimura Y: Pharmacognostical studies on umbelliferous plants. XX. Studies on Chinese drug 'bvaku-shi'. 5. On the coumarins of the roots of Angelica formosana Boiss. and A. anomala Lall. Yakugaku Zasshi 83: 611-614, 1963 (In Japanese)

31. Wang MY, Jia MR, Ma YY, Tang SW, Jiang GH and Li XB: Studies on analgestic components of Radix Angelicae dahuricae. Chin Pharm J 40: 583-587, 2005 (In Chinese).

32. Sun X, Zhang C, Li J, Feng J, Zhou H, Fu S and Chen W. Chemical constituents from Peucedanum decursivum. Chin Trad Herb Drugs 44: 2044-2047, 2013 (In Chinese).

33. Jin MH, Moon TC, Hong TG, Park KM, Son JK and Chang HW: 5-Methoxy-8-(2-hydroxy-3-buthoxy-3-methylbutyloxy)-psoralen isolated from Angelica dahurica inhibits cyclooxygenase- 2 and 5-lipoxygenase in mouse bone marrow-derived mast cells. Arch Pharm Res 31: 617-621, 2008

34. Moon TC, Jin MH, Son JK and Chang HW: The effects of isoimperatorin isolated from Angelicae dahuricae on cyclooxygenase- 2 and 5-lipoxygenase in mouse bone marrow-derived mast cells. Arch Pharm Res 31: 210-215, 2008. 